\title{
Dopamine Overflow in the Nucleus Accumbens during Extinction and Reinstatement of Cocaine Self-Administration Behavior
}

\author{
Janet L. Neisewander, Ph.D., Laura E. O'Dell, M.A., Ly T.L. Tran-Nguyen, M.A.,
} Edward Castañeda, Ph.D., and Rita A. Fuchs, B.S.

Both cocaine and cocaine-associated stimuli can reinstate extinguished self-administration behavior in animals. It has been suggested that reinstatement of drug-seeking behavior may be mediated by enhanced dopamine (DA)

neurotransmission. To examine this hypothesis, DA overflow was measured in the nucleus accumbens (NAc) of rats during both extinction and cocaine-induced reinstatement of self-administration behavior. Rats were either allowed to self-administer cocaine for 3 hours daily for 14 days, or they received yoked administration of saline. A stimulus light above the lever was illuminated during drug delivery. Baseline DA overflow was measured in the
$N A c$, using in vivo microdialysis 7 to 8 days after the last self-administration session. The rats were then placed into the operant chambers and allowed to respond in extinction for 90 minutes, during which responses resulted in presentation of the stimulus light. The rats then received a cocaine injection that reinstated self-administration behavior. Contrary to our hypothesis, cocaine-experienced animals exhibited less DA overflow in the NAc relative to controls during both extinction and reinstatement.

(C) 1996 American College of Neuropsychopharmacology [Neuropsychopharmacology 15:506-514, 1996]
KEY WORDS: Cocaine withdrawal; Cocaine conditioning; Microdialysis; Dopamine; Nucleus accumbens;

Reinstatement; Cocaine-seeking behavior

Self-reports in humans indicate that drug craving is an important factor in maintaining and reinstating drug abuse (Gawin 1991; Markou et al. 1993). Although little is known about the mechanisms involved in drug craving, anecdotal reports, as well as laboratory studies, indicate that exposure to drug-associated stimuli or to the

From the Department of Psychology, Arizona State University, Tempe, Arizona.

Address correspondence to: Janet L. Neisewander, Ph.D., Department of Psychology, Arizona State University, Box 871104, Tempe, AZ 85287-1104.

Received March 6, 1996; revised April 18, 1996; accepted April 29, 1996. drug itself can elicit drug craving (Childress et al. 1988; Ehrman et al. 1992; Jaffe et al. 1989; Kranzler and Bauer 1992). Similarly, extinguished self-administration behavior in animals is reinstated after presentation of stimuli paired previously with drug self-administration or after a priming injection of the drug itself (Davis and Smith 1976; de Wit and Stewart 1981; Pickens and Harris 1968; Stretch and Gerber 1973). Thus, reinstatement of drug self-administration behavior may provide an animal model for investigating the neural mechanisms of drug craving (Markou et al. 1993).

Previous research has demonstrated that extinguished opiate or psychomotor stimulant self-administration behavior is reinstated by priming injections of either indirect or direct dopamine (DA) receptor agonists, suggesting that an increase in DA neurotransmission may be involved in reinstating drug-seeking be- 
havior (de Wit and Stewart 1981; Gerber and Stretch 1975; Wise et al. 1990). Localization studies indicate that these effects are mediated, at least in part, by the mesolimbic dopaminergic pathway that originates in the ventral tegmental area (VTA) and terminates in the nucleus accumbens (NAc). Injections of amphetamine into the NAc or morphine into the VTA increase DA neurotransmission in the NAc and reinstate extinguished cocaine and heroin self-administration behavior (Stewart 1984; Stewart and Vezina 1988).

Little is known about the neural mechanisms involved in reinstatement by drug-associated stimuli. It has been suggested that stimuli paired contiguously with drug administration may acquire the ability to elicit activity from neuronal systems activated by the drug through classical conditioning (Eikelboom and Stewart 1982; Stewart et al. 1984). If this is the case, then exposure to cocaine-associated stimuli may elicit conditioned enhancement of DA neurotransmission in the NAc, similar to cocaine itself. Consistent with this hypothesis, results from in vivo electrochemistry studies suggest that DA-related signals in the NAc increase in anticipation of cocaine self-administration and in response to presentation of a stimulus light paired previously with cocaine self-administration (Gratton and Wise 1994; Kiyatkin 1995; Kiyatkin and Stein 1994). However, electrophysiologic studies indicate that increased neurotransmission in the NAc in anticipation of cocaine self-administration is not DA-mediated (Chang et al. 1994). Other procedures for investigating drugconditioned responses include: (1) examining whether cocaine-induced behaviors are altered in a drug-paired environment relative to a neutral environment (i.e., context-dependent changes), or (2) examining whether a drug-paired environment elicits changes in behaviors affected by the drug in the absence of the drug itself. Microdialysis studies have found that animals exhibit context-dependent sensitization of stimulant behaviors and conditioned enhancement of DA neurotransmission in the NAc after cocaine administration (Fontana et al. 1993). In contrast, no evidence of conditioned DA neurotransmission has been found in animals exhibiting conditioned stimulant behaviors after saline administration in a cocaine-paired environment (Brown and Fibiger 1992). The discrepancy between the latter two dialysis studies may have been due to testing animals in a cocaine state versus a drug-free state. Presence of drug during testing may result in increased sensitivity for detecting conditioned enhancement of DA overflow (Fontana et al. 1993). However, it is also possible that different neural mechanisms are involved in behavioral responses, including craving, elicited by environmental stimuli alone versus those elicited by cocaine (Markou et al. 1993).

The present experiment further examined the hypothesis that cocaine-associated stimuli elicit condi- tioned enhancement of DA neurotransmission in the NAc. DA overflow in the NAc was measured using in vivo microdialysis during response-contingent presentations of stimuli paired previously with cocaine selfadministration, first alone and then after a priming injection of cocaine. Baseline DA overflow was measured in the NAc using in vivo microdialysis 7 to 8 days after the last self-administration session. The rats were then placed into the operant chambers and tested for extinction for 90 minutes, during which responses resulted in presentation of the stimulus light. They then received a priming injection of cocaine $(10 \mathrm{mg} / \mathrm{kg}, \mathrm{IP})$ and testing continued for 90 minutes. Dialysate samples were collected every 15 minutes throughout both extinction and reinstatement test phases.

\section{MATERIALS AND METHODS}

\section{Animals}

Male Sprague-Dawley rats (Charles River Breeding Labs, Wilmington, MA) weighing 250 to $300 \mathrm{~g}$ were single-housed in a climate-controlled colony room with a 12-hour light/dark cycle. The housing conditions and care of the animals were consistent with those specified in the "Guide for the Care and Use of Laboratory Animals" adopted by the National Institutes of Health. The animals were acclimated to handling for 5 days before beginning the experiment.

\section{Food Training}

The animals were placed on a 23-hour food deprivation schedule 2 to 3 days prior to training. They were trained to lever press for a food pellet $(45 \mathrm{mg}$; Noyes, Lancaster, $\mathrm{NH}$ ) initially on an FR 1 and progressing to a VI 10 schedule across 3 consecutive days. They were given food ad libitum after the session on day 3 .

\section{Surgery}

Three to 4 days after completing the food training procedure, animals were anesthetized with pentobarbital $(50 \mathrm{mg} / \mathrm{kg}$, IP) in combination with atropine sulfate (10 $\mathrm{mg} / \mathrm{kg}$, IP). Catheters were implanted into the jugular vein and exited through an incision across the head as described by Depoortere et al. (1993). After implanting the catheters, the animals were placed into a stereotaxic instrument and the top of the skull was exposed and dried. Guide cannulae (21-gauge stainless steel) were then implanted bilaterally into the NAc using the following coordinates derived from the Paxinos and Watson atlas (1986): $+2.2 \mathrm{~mm} \mathrm{~A}$ and $\pm 1.6 \mathrm{~mm} \mathrm{ML}$ with respect to Bregma, and $-4.5 \mathrm{~mm} \mathrm{~V}$ from the top of the skull. Three screws were anchored approximately 5 
$\mathrm{mm}$ around the cannulae. The cannulae and the metal end of the catheter were secured by applying dental acrylic over the skull and screws. Approximately 12 hours after surgery, wire stylets were placed into the guide cannulae to maintain patency. Throughout the remainder of the experiment, catheters were flushed daily with a solution $(0.1 \mathrm{ml})$ of heparinized saline $(30 \mathrm{U} / \mathrm{ml})$, streptokinase $(4 \mathrm{mg} / \mathrm{ml})$, and ticarcillin disodium $(400$ $\mathrm{mg} / \mathrm{ml}$ ) in order to maintain patency. Catheters were sealed when not in use with a cap composed of tygon tubing. The rats were allowed 3 to 4 days to recover from surgery before beginning self-administration training, and they were handled each recovery day.

\section{Self-Administration Training}

Rats were randomly assigned to groups receiving either response-contingent cocaine $(0.75 \mathrm{mg} / \mathrm{kg} / 0.1 \mathrm{ml}$ infusion; $n=10$ ) or an equal volume of saline contingent upon schedule completions made by an animal in the cocaine group $(n=7)$. They received daily 3 -hour sessions of training for 14 consecutive days. The animals were placed into operant chambers that were housed within sound-attenuating chambers each equipped with a fan. The operant chambers contained a response lever, a stimulus light located $4 \mathrm{~cm}$ above the lever, and a house light located on the wall opposite to the lever (MedAssociates, St. Albans, VT). Animals were deprived of food before the onset of the dark cycle the evening before the first session and were given food ad libitum after the first session and throughout the remainder of the experiment. At the beginning of the first session, rats in the cocaine group received a noncontingent priming infusion of cocaine $(0.75 \mathrm{mg} / \mathrm{kg} / 0.1 \mathrm{ml}$ infusion). They were initially trained on an FR 1 schedule of cocaine reinforcement on days 1 to 3 depending on their performance. After animals received at least 15 reinforcers on a given day on the FR 1 schedule, the schedule was increased to an FR 5. Six out of 10 animals were placed on the FR 5 schedule during the first training session. The remaining four animals received one to three priming injections of cocaine per session until they began responding on the FR 5 schedule (i.e., a maximum of six sessions). No priming infusions were given after session 6 .

Each schedule completion by an animal in the cocaine group resulted in simultaneous termination of the house light and illumination of the stimulus light, followed 1 second later by activation of the infusion pump. The infusion was delivered over a 6-second period, after which the stimulus light and the infusion pump were inactivated. After a 20 -second timeout period, the house light was illuminated. Controls received presentation of the same stimulus complex contingent upon schedule completions by an animal in the cocaine group, except that saline was infused rather than cocaine.

\section{Probe Implantation}

Forty-eight hours before testing, animals were anesthetized with a mixture of ketamine and xylazine (19 and 6 $\mathrm{mg} / \mathrm{kg}$, IM, respectively). Dialysis probes constructed using the method described by Robinson and Camp (1991) were then inserted into the guide cannulae to a depth of $8 \mathrm{~mm}$ ventral from the surface of the skull and were secured to the guide cannulae using dental acrylic. The cellulose dialysis membrane (Spectra/Por Spectrum Medical) included a 2-mm effective length and a $0.25 \mathrm{~mm}$ epoxy plug. In vitro recoveries of DA and monoamine metabolites consistently ranged from. $10 \%$ to $20 \%$. The inlet and outlet tubings of the probes were contained within a steel coiled tether. The inlet tubings were attached to a dual-channel liquid swivel, and the outlet silica tubings were inserted into collection vials located $25 \mathrm{~cm}$ above the animal's head, such that the vials could be easily exchanged without interfering with the animal's behavior. In order to relieve tension from the tubings, a wire was secured to the tether and cemented to the animal's skull using dental acrylic. The swivels were secured within a metal ring holder with screws. The extending screw heads of the swivel holder were then placed into fittings on an arm suspended over the animal's home cage. Metal latches were placed over the screw heads such that the swivel holder was secured, free to rotate vertically, and could be easily removed and transferred to an arm above the operant chambers. After implantation, Ringers solution $\left(128.3 \mathrm{mmol} / \mathrm{L} \mathrm{NaCl}, 1.35 \mathrm{mmol} / \mathrm{L} \mathrm{CaCl}_{2}, 2.68 \mathrm{mmol} / \mathrm{L}\right.$ $\mathrm{KCl}$, and $2.0 \mathrm{mmol} / \mathrm{L} \mathrm{MgCl}_{2}, \mathrm{pH} 7.3$ ) was perfused through the probes at a rate of $0.15 \mu \mathrm{l} / \mathrm{min}$. The animals were returned to their home cages until testing.

\section{Dialysate Measures during Extinction and Reinstatement of Self-Administration Behavior}

Dialysis measures were taken 7 to 8 days after the last self-administration session while animals were being tested for extinction and reinstatement of self-administration behavior. The animals were transported to the self-administration room, and the probes were perfused with fresh Ringers solution at a rate of $1.5 \mu \mathrm{l} /$ minute. After a 30-minute adaptation period, four 15-minute baseline samples were collected. The animals were then transferred to the operant chambers. Schedule completions (i.e., FR 5) by animals in the cocaine group resulted in presentation of the stimulus complex described previously, except that the IV lines were not connected to the infusion syringe so no drug was delivered after activation of the infusion pump (i.e., extinction phase). Saline infusions were not administered be- 
cause the liquid swivel needed for these infusions was used to perfuse Ringers solution through the dialysis probes. Ninety minutes later, all animals received an injection of cocaine $(10 \mathrm{mg} / \mathrm{kg}$, IP), and responding was then measured for 90 minutes (i.e., reinstatement phase). Throughout both test phases, 15-minute dialysate samples were collected, stored on ice, and typically assayed within 1 hour.

High performance liquid chromatography (HPLC) with electrochemical detection was used to assay dialysis samples. The system consisted of an ESA Model 420 dual piston HPLC pump (Bedford, MA), an $8 \mathrm{~cm}$ ESA Catecholamine HR 80 reverse-phase column $(3 \mu \mathrm{m} \mathrm{C18}$ particles $4.6 \mathrm{~mm}$ I.D.), and an ESA Model $5200 \mathrm{Cou}-$ lochem II detector, including a Model 5021 Conditioning Cell positioned in front of a dual electrode Model 5011 High Sensitivity Analytical Cell. The mobile phase consisted of $60 \mathrm{mmol} / \mathrm{L} \mathrm{NaH}_{2} \mathrm{PO}_{4}, 30 \mathrm{mmol} / \mathrm{L}$ citric acid, $0.1 \mathrm{mmol} / \mathrm{L}$ EDTA, $30 \mathrm{mg} / \mathrm{L}$ SDS, $20 \% \mathrm{MeOH}$, at a $\mathrm{pH}$ of 4.2. The conditioning cell was set to oxidize at $+100 \mathrm{mV}$ in order to reduce background noise. The oxidation of DOPAC, HVA, and 5-HIAA was measured by the first analytical cell set to $+340 \mathrm{mV}$ with a filter setting of 10 seconds. Reduction of DA was quantified at the second electrode set to $-350 \mathrm{mV}$ with a filter setting of 10 seconds. The total elution time ranged from 7 to 10 minutes. Peak heights were recorded on an Alltech Linear Model 1200 dual pen recorder with a chart speed setting of $20 \mathrm{~cm} /$ hour and maximum pen deflections were equivalent to $1 \mathrm{~V}$. Peak heights of a standard consisting of $4 \mathrm{pg} / \mu \mathrm{l}$ of DA and $200 \mathrm{pg} / \mu \mathrm{l}$ of DOPAC, 5HIAA and HVA were used to calculate the concentration of each compound based on linear regression analyses.

\section{Catheter Patency and Probe Placement}

Patency of catheters was verified periodically by administering $0.1 \mathrm{ml}$ sodium brevital $(1.7 \mathrm{mg} / \mathrm{ml}, \mathrm{IV})$. This dose is only potent enough to briefly anesthetize animals when administered IV. Probe placements were verified in coronal brain sections stained with cresyl violet.

\section{Statistical Analyses}

Differences in the number of schedule completions by experimental and control animals were analyzed using nonparametric Kruskall-Wallis ANOVAs, and subsequent pairwise comparisons were made using MannWhitney U tests. Dialysate measures were analyzed using repeated measures ANOVAs with drug history as a between groups variable and 15-minute interval as a repeated measure. Significant interactions were further analyzed by ANOVAs, including data from (1) baseline and the first 15-minute interval during extinction, (2) 15minute intervals during extinction, and (3) 15-minute in- tervals during reinstatement. Subsequent pairwise comparisons were made using Fisher LSD tests.

\section{RESULTS}

\section{Probe Placements}

Dialysis probes for all animals included in this experiment were located within $0.5 \mathrm{~mm}$ of the targeted site. The approximate position of the effective length of the dialysis membranes is illustrated in Figure 1.

\section{Behavior}

The mean number of cocaine infusions ( \pm SEM) for the entire 14-day self-administration regimen was 477.7 $( \pm 54.9)$. Most animals acquired a stable pattern of cocaine self-administration by day 7 , such that the mean number of cocaine infusions across the remaining days $( \pm$ SEM) fell within the range of $35.7( \pm 3.2)$ and 40.2 ( \pm 4.3 ) on days 8 and 10 , respectively.

The mean number of FR 5 schedule completions during both extinction and reinstatement test phases is illustrated in Figure 2 (top panel). After 7 to 8 days of withdrawal from cocaine self-administration, the cocaine group exhibited self-administration behavior after being placed into the operant chambers that extinguished in nearly all animals after 90 minutes. The co-

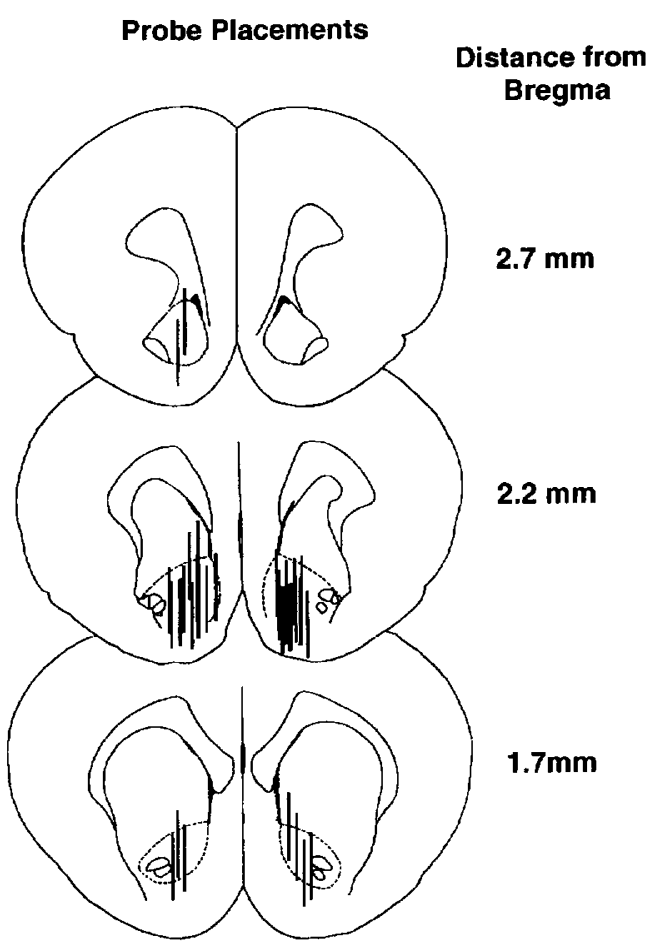

Figure 1. Approximate placements of the effective length of the dialysis membranes. Drawings were adapted from illustrations in the Paxinos and Watson (1986) atlas. 

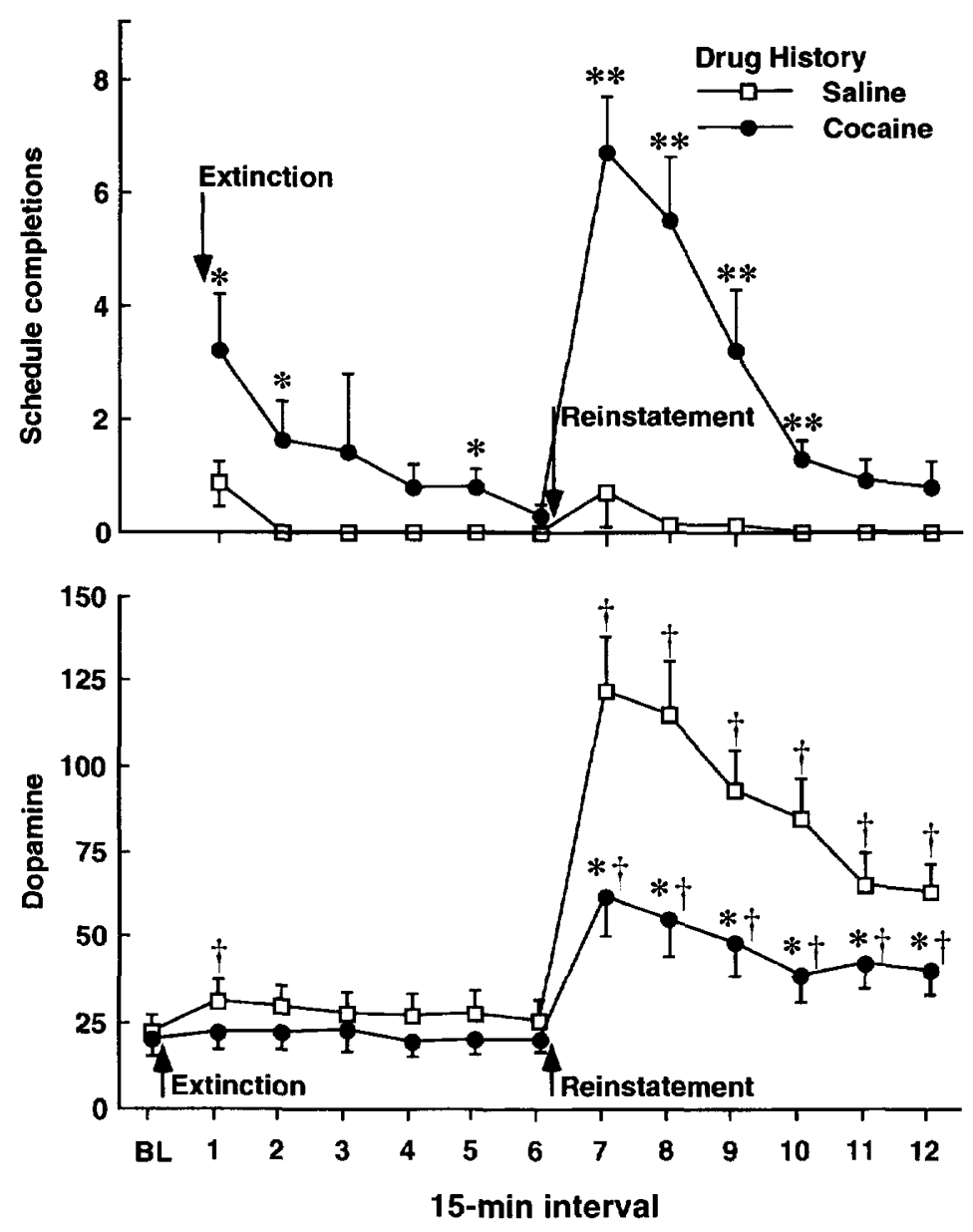

Figure 2. Number of FR 5 schedule completions $( \pm$ SEM) and DA overflow ( $\mathrm{fmol} / \mathrm{min} \pm$ SEM) in animals with a history of yoked saline administration (open squares) or cocaine self-administration (closed circles) across 15-minute intervals during baseline (BL), extinction, and reinstatement test phases. Animals were tested after a 7 to 8 -day withdrawal period from a 14-day regimen of either selfadministered cocaine or yoked administration of saline. The extinction phase began after placing the animals into the operant chambers, and the reinstatement phase began after the animals received an injection of cocaine $(10 \mathrm{mg} / \mathrm{kg}$, IP) immediately after the sixth 15-minute interval. Schedule completions by animals in the cocaine group resulted in presentation of the stimulus complex paired previously with cocaine self-administration to both the cocaine and yoked control animals. Responses by control animals had no scheduled consequences. For schedule completions, asterisks $\left.{ }^{*}\right)$ represent a significant difference from saline controls (MannWhitney U tests, $\left.{ }^{*} p<.05,{ }^{* *} p<.01\right)$. For DA overflow, asterisks $\left({ }^{*}\right)$ represent a significant difference from saline controls (Fisher LSD test, $p<.05$ ), and daggers $(t)$ represent a significant difference from respective baseline measures (Fisher LSD test, $p<05)$. caine group exhibited significantly more schedule completions relative to controls during intervals 1,2 , and 5 $(p<.05$, Mann-Whitney $U$ tests). Only two animals in the cocaine group exhibited responding during the sixth 15-minute interval. Self-administration behavior was reinstated in the cocaine group after the priming injection of cocaine. The cocaine group exhibited significantly more schedule completions relative to controls during the first hour of this test phase $(p<.05$, MannWhitney U tests).

\section{Dialysate Measures}

DA overflow in the NAc during baseline, extinction, and reinstatement of self-administration behavior is illustrated in Figure 2 (bottom panel). There were no significant differences in the four baseline dialysate samples, and therefore, the average of these samples was used as the baseline value. The overall ANOVA of DA levels indicated a significant drug history by 15 -minute interval interaction $(F[12,180]=9.8, p<.0001)$. Subsequent analyses indicated that there were no significant differences between groups during baseline (F[1,16] = 0.79 , NS), nor across the 15 -minute intervals during the extinction phase of testing $(\mathrm{F}[5,75]=0.61, \mathrm{NS})$. However, an analysis of DA levels across baseline and the first 15-minute interval during extinction revealed a significant drug history by 15 -minute interval interaction $(\mathrm{F}[1,15]=7.3, p<.05)$. DA levels increased in control animals during the first 15-minute interval of testing relative to baseline ( $p<.05$, Fisher LSD test), whereas DA levels in cocaine animals did not change. After the injection of cocaine (i.e., reinstatement phase), both groups exhibited a significant increase in DA levels relative to baseline that persisted throughout the reinstatement test phase ( $p<.05$, Fisher LSD test). Furthermore, the increase in DA levels was significantly lower in the cocaine group ( $208 \%$ increase) relative to controls ( $447 \%$ increase) and remained lower throughout this test phase ( $p<.05$, Fisher LSD test). Analysis of DA levels across the 15-minute intervals of the reinstatement phase revealed a significant drug history by 15 -minute interval interaction $(F[5,75]=3.7, p<.005)$. Both groups exhibited a decrease in DA levels across time during the reinstatement phase, however, the timedependent decrease occurred earlier and to a greater extent in controls relative to the cocaine group. Specifically, a significant decrease $(23.5 \%)$ in DA levels was 
evident in controls by the ninth interval relative to the seventh interval, and a further significant decrease $(32.1 \%)$ was evident by the 11 th interval relative to the ninth interval ( $p<.05$, Fisher LSD test). In contrast, a significant decrease $(34.4 \%)$ in DA levels was evident in the cocaine group by the 10th interval relative to the seventh interval ( $p<.05$, Fisher LSD test) and did not change significantly thereafter.
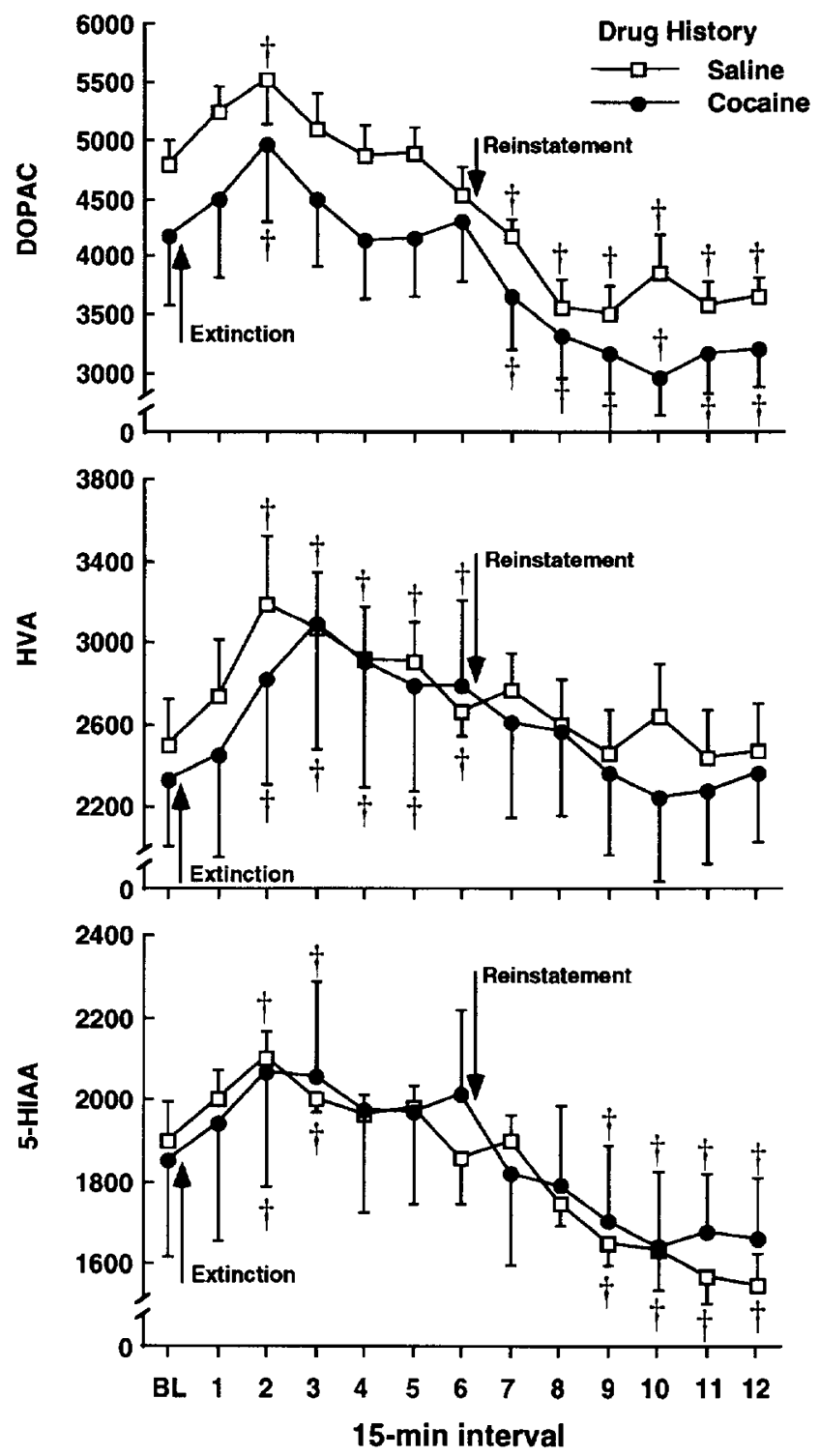

Figure 3. DOPAC, HVA, and 5-HIAA overflow ( $\mathrm{fmol} / \mathrm{min}$ \pm SEM) in the NAc in animals with a history of yoked saline administration (open squares) or cocaine self-administration (closed circles) across 15-minute intervals during baseline (BL), extinction, and reinstatement test phases. The latter two phases are described in the caption for Figure 2. Daggers $(t)$ represent a significant difference from baseline collapsed across treatment groups (Fisher LSD test, $p<.05$ ).
DOPAC, HVA, and 5-HIAA overflow in the NAc across test phases is illustrated in Figure 3. Levels of these metabolites were not altered by previous history of cocaine self-administration. In each case, there were no significant effects of drug history, nor significant interactions between 15-minute interval and drug history. However, there was a significant time-dependent change across 15-minute intervals in levels of DOPAC $(\mathrm{F}[1,12]=$ 23.3, $p<.0001)$, HVA $(\mathrm{F}[1,12]=6.6, p<.0001)$, and 5 -HIAA $(\mathrm{F}[1,12]=12.3, p<.0001)$ regardless of drug history. In each case, metabolite levels increased relative to baseline within 30 minutes after animals were placed into the chambers ( $p<.05$, Fisher LSD test). After the cocaine injection, DOPAC levels decreased relative to baseline immediately and remained depressed throughout the reinstatement phase $(p<.05$, Fisher LSD test). 5-HIAA levels decreased within 45 minutes and remained depressed throughout the reinstatement phase $(p<.05$, Fisher LSD test).

\section{DISCUSSION}

After 7 to 8 days of withdrawal, cocaine animals (i.e., animals with a history of cocaine self-administration) exhibited responding for the stimulus complex paired previously with cocaine delivery, and this responding was extinguished in most animals within the 90-minute extinction test phase. Contrary to our hypothesis, these animals failed to exhibit an increase in DA overflow in the NAc during this test phase, whereas saline controls did exhibit an increase in DA overflow during the first 15 minutes. These findings suggest that exposure to drug-associated stimuli alone does not result in conditioned enhancement of DA neurotransmission in the NAc, consistent with a previous report (Brown and Fibiger 1992). In fact, the lack of an increase in DA overflow in cocaine animals despite the increase observed in controls suggests that cocaine-associated stimuli may elicit a compensatory conditioned inhibition of DA neurotransmission in the NAc. This interpretation is tempered, however, in light of an in vivo electrochemistry study indicating an increase in DA-related signals after presentation of a stimulus light paired previously with cocaine self-administration (Gratton and Wise 1994). DA-related electrochemical signals typically decrease after delivery of the cocaine reinforcer (Gratton and Wise 1994; Kiyatkin 1995; Kiyatkin and Stein 1994). Thus, it is possible that cocaine animals experience a conditioned increase in DA neurotransmission as they perform the operant response, and a conditioned decrease in DA neurotransmission after presentation of cocaine-paired stimuli (i.e., secondary reinforcers), consistent with the phasic changes in DA-related signals observed during cocaine self-administration. The dialy- 
sis measures in the present study are not sensitive enough to detect these putative momentary changes, and may reflect a net decrease in DA neurotransmission. This explanation seems unlikely, however, because dialysis studies (Di Ciano et al. 1995; Parsons et al. 1995; Pettit and Justice 1989, 1991; Wise et al. 1995), as well as an electrochemical study presenting data per longer unit of time (Di Ciano et al. 1995), indicate sustained elevation of DA in the NAc during cocaine selfadministration sessions. Electrochemical measures are not as specific for DA as the dialysis measures, and may be contaminated by the DA metabolite DOPAC (Gratton and Wise 1994; Kiyatkin 1995). If this were the case, then an increase in the DOPAC signal after presentation of the cocaine-paired light would be consistent with the increase in DOPAC levels observed in the present study. However, both saline and cocaine animals exhibited an increase in DOPAC, as well as HVA and 5HIAA, within 30 minutes of testing, indicating the increase in DOPAC was not specific to conditioning.

Alternative explanations for the difference in DA overflow between saline and cocaine animals include differences in stress or arousal. It is possible that noncontingent presentation of the stimulus complex is stressful to control animals and may lead to an increase in DA overflow in the NAc, as has been reported for other stressful stimuli (Sorg and Kalivas 1991). It seems more likely, however, that the increase in DA overflow in control animals is due to the dishabituating effect of transferring the animals from their home cage to the operant chamber because similar changes have been observed in animals transferred to a familiar, perhaps nonstressful, environment (e.g., Brown and Fibiger 1992). Thus, it is possible that animals withdrawn from chronic cocaine administration are less aroused by changes in environmental stimuli relative to controls. Indeed, several studies indicate that animals withdrawn from chronic cocaine administration are less active and habituate more readily than controls (Bozarth 1989; Fung and Richard 1994; Neisewander et al. 1994, 1996). Future research is planned to examine whether noncontingent presentation of cocaine-paired stimuli decreases DA neurotransmission in animals that have extinguished responding and presumably habituated to the operant chambers. In any case, the present findings strongly suggest that stimuli paired with cocaine selfadministration do not elicit conditioned enhancement of DA neurotransmission in the NAc.

The priming injection of cocaine $(10 \mathrm{mg} / \mathrm{kg}$, IP) reinstated responding for the stimulus complex in cocaine animals. Both the cocaine and control groups exhibited an increase in DA overflow in the NAc during the reinstatement test phase that was significantly greater in control animals relative to cocaine animals. It is unclear whether the diminished effectiveness of cocaine in producing enhanced DA neurotransmission is a condi- tioned or an unconditioned effect. In either case, the findings conflict with Fontana et al. (1993) who reported conditioned enhancement of cocaine-induced DA overflow in the NAc of animals that had previously received an injection of cocaine in the test environment and saline later in the home cage relative to control groups that had received an injection of saline in the test environment and either saline or cocaine later in the home cage. This discrepancy may be due to differences in the passive versus self-administration regimens used during conditioning, with the former producing conditioned enhancement and the latter producing conditioned and/or unconditioned tolerance to cocaineinduced DA neurotransmission. Indeed, several studies have demonstrated sensitized DA neurotransmission in the NAc after various repeated passive administration regimens of cocaine (Akimoto et al. 1989; Kalivas and Duffy 1990, 1993; Keller et al. 1992; Peris et al. 1990; Pettit et al. 1990). In contrast, a decrease in DA neurotransmission in the NAc has been reported during and within 1 day of a cocaine self-administration session relative to baseline levels (Parsons et al. 1995; Weiss et al. 1992a,b), to drug-naive controls (Hurd et al. 1989), or to cocaine-yoked controls (Dworkin et al. 1995; Weiss et al. 1992a). Studies that have not observed a decrease in DA neurotransmission within 1 day of a cocaine selfadministration session have found that a decrease emerges after a 7-day withdrawal period (Meil et al. 1995), and an increase emerges after a 21-day withdrawal period (Hooks et al. 1994). There are two factors that vary between studies reporting a decrease versus an increase in sensitivity to cocaine during withdrawal: length of withdrawal period and the presence or absence of conditioning cues during testing. It is possible that biphasic time-dependent changes in sensitivity to cocaine may occur after withdrawal from self-administered cocaine, with a decrease occurring early on (Meil et al. 1995, present findings) and an increase occurring at later time points during withdrawal (Hooks et al. 1994). It is also possible that conditioned inhibition of DA in the NAc may result in decreased sensitivity to cocaine when animals are tested in the presence of conditioned stimuli (Meil et al. 1995; present findings), whereas enhanced sensitivity to cocaine may be evident when animals are tested in the absence of conditioned stimuli (Hooks et al. 1994).

Environmental factors may also affect the particular behaviors expressed during testing (e.g., Ohmori et al. 1995). Both Fontana et al. (1993) and Hooks et al. (1994) tested animals in activity cages and reported enhanced DA neurotransmission and sensitized motor responses. In fact, Hooks et al. (1994) found that the sensitized motor responses were correlated with DA levels in the NAc. Although motor behavior was not measured in the present study, it is possible that animals exhibit less motor activity in operant chambers relative to that ob- 
served in activity cages, and this may account for the differences in DA neurotransmission observed among these studies.

In the present study, drug-seeking behavior was evident during both extinction and reinstatement. However, no change, or perhaps a decrease, in DA neurotransmission occurred during extinction and an increase in DA neurotransmission occurred during reinstatement. These findings suggest that there may be no relationship between DA neurotransmission in the NAc and drug-seeking behavior. However, it is possible that drug-seeking behavior elicited by cocaine-paired stimuli involves a different neural mechanism than drugseeking behavior elicited by cocaine itself. If the findings under these conditions are considered independently, they suggest that stimulus-elicited behavior either does not involve DA in the NAc or involves conditioned inhibition of DA neurotransmission in the NAc, whereas cocaine-elicited behavior may involve enhanced DA neurotransmission in the NAc. Alternatively, it is possible that both drug-paired stimuli and cocaine activate the same neural pathway for reinstatement of drugseeking behavior, and that this pathway is modulated by cocaine-induced increases in DA in the NAc. For instance, Robbins and colleagues have reported that lesions of the basolateral amygdala disrupt responding for a conditioned reinforcer, however intra-accumbens administration of amphetamine reinstates responding (Everitt and Robbins 1992; Robbins et al. 1989). Thus, it is possible that reinstatement of drug-seeking behavior by both cocaine-paired stimuli and cocaine itself is mediated by the basolateral amygdala, and enhanced DA neurotransmission in the NAc after cocaine further amplifies drug-seeking behavior mediated by the amygdala. Further research is needed to investigate these hypotheses.

\section{ACKNOWLEDGMENTS}

We gratefully acknowledge Tom Shepherd, Sam Leifheit, Lewis Bizo, and Peter Killeen for their advice and help with our computer programs and equipment. We also thank Amy Sussman, Sheila Specio, Scott Harrington, and Nichole Manders for their assistance with data collection and analysis. This research was supported by USPHS Grant DA 07730, National Institute of Mental Health/Minority Neuroscience Training Program Grant MH-19547, and the Howard Hughes Medical Institute Undergraduate Biological Sciences Education Program.

\section{REFERENCES}

Akimoto K, Hamamura T, Otsuki S (1989): Subchronic cocaine treatment enhances cocaine-induced dopamine efflux, studied by in vivo intracerebral dialysis. Brain Res 490:339-344
Bozarth MA (1989): New perspectives on cocaine addiction: Recent findings from animal research. Can J Physiol 67:1158-1167

Brown EE, Fibiger HC (1992): Cocaine-induced conditioned locomotion: Absence of associated increases in dopamine release. Neuroscience 48:621-629

Chang J-Y, Sawyer SF, Lee R-S, Woodward DJ (1994): Electrophysiological and pharmacological evidence for the role of the nucleus accumbens in cocaine self-administration in freely moving rats. J Neurosci 14:1224-1244

Childress AR, McLellan AT, Ehrman R, O'Brien CP (1988): Classically conditioned responses in opioid and cocaine dependence: A role in relapse? In Learning Factors in Substance Abuse. NIDA Research Monograph 94, Washington, DC, U.S. Government Print Office, pp. 25-43

Davis WM, Smith SG (1976) Role of conditioned reinforcers in the initiation, maintenance and extinction of drugseeking behavior. Pavlov J Biol Sci 11:222-236

Depoortere RY, Li D-H, Lane JD, Emmett-Oglesby MW (1993): Parameters of self-administration of cocaine in rats: Time course and dose-response determination using a multi-dose method. Drug Alcohol Depend 32:247-256

de Wit H, Stewart J (1981): Reinstatement of cocaine-reinforced responding in the rat. Psychopharmacology 75: 134-143

Di Ciano P, Coury A, Depoortere RY, Egilmez Y, Lane JD, Emmett-Oglesby MW, Lepiane FG, Phillips AG, Blaha CD (1995): Comparison of changes in extracellular dopamine concentrations in the nucleus accumbens during intravenous self-administration of cocaine or d-amphetamine. Behav Pharmacol 6:311-322

Dworkin SI, Co C, Smith JE (1995): Rat brain neurotransmitter turnover rates altered during withdrawal from chronic cocaine administration. Brain Res 682:116-126

Ehrman RN, Robbins SI, Childress AR, O'Brien CP (1992): Conditioned responses to cocaine-related stimuli in cocaine abuse patients. Psychopharmacology 107:523-529

Eikelboom R, Stewart J (1982): Conditioning of drug-induced physiological responses. Psychol Rev 89:507-528

Everitt BJ, Robbins TW (1992): Amygdala-ventral striatal interactions and reward-related processes. In Aggleton JP (ed), Neurobiological Aspects of Emotion, Memory, and Mental Dysfunction. New York, Wiley-Liss, pp 401-429

Fontana DJ, Post RM, Pert A (1993): Conditioned increases in mesolimbic dopamine overflow by stimuli associated with cocaine. Brain Res 629:31-39

Fung YK, Richard LA (1994): Behavioural consequences of cocaine withdrawal in rats. J Pharm Pharmacol 46:150-152

Gawin FH (1991): Cocaine addiction: Psychology and neurophysiology. Science 251:1580-1586

Gerber GJ, Stretch R (1975): Drug-induced reinstatement of extinguished self-administration behavior in monkeys. Pharmacol Biochem Behav 3:1055-1061

Gratton A, Wise RA (1994): Drug- and behavior-associated changes in dopamine-related electrochemical signals during intravenous cocaine self-administration in rats. J Neurosci 14:4130-4146

Hooks MS, Duffy P, Striplin C, Kalivas PW (1994): Behav- 
ioral and neurochemical sensitization following cocaine self-administration. Psychopharmacology 115:265-272

Hurd YL, Weiss F, Koob GF, And NE, Ungerstedt U (1989): Cocaine reinforcement and extracellular dopamine overflow in rat nucleus accumbens: An in vivo microdialysis study. Brain Res 498:199-203

Jaffe JH, Cascella NG, Kumar KM, Sherer MA (1989): Cocaine-induced cocaine craving. Psychopharmacology 97:59-64

Kalivas PW, Duffy P (1990): The effects of acute and daily cocaine treatment on extracellular dopamine in the nucleus accumbens. Synapse 5:48-58

Kalivas PW, Duffy P (1993): Time course of extracellular dopamine and behavioral sensitization to cocaine. I. Dopamine axon terminals. J Neurosci 13:266-275

Keller RW, Maisonneuve IM, Carlson JN, Glick SD (1992): Within subject sensitization of striatal dopamine release after single injection of cocaine: An in vivo microdialysis study. Synapse 11:20-34

Kiyatkin EA (1995): Functional significance of mesolimbic dopamine. Neurosci Biobehav Rev 19:573-598

Kiyatkin EA, Stein EA (1994): Biphasic changes in mesolimbic dopamine signal during cocaine self-administration. NeuroReport 5:1005-1008

Kranzler HR, Bauer LO (1992): Bromocriptine and cocaine cue reactivity in cocaine-dependent patients. Br J Addict $87: 1537-1548$

Markou A, Weiss F, Gold LH, Caine SB, Schulteis G, Koob GF (1993): Animal models of drug craving. Psychopharmacology 112:163-182

Meil WM, Roll JM, Grimm JW, Lynch AM, See RE (1995): Tolerance-like attenuation to contingent and noncontingent cocaine-induced elevation of extracellular dopamine in the ventral striatum following 7 days of withdrawal from chronic treatment. Psychopharmacology 118:338346

Neisewander JL, Lucki I, McGonigle P (1994): Time-dependent changes in sensitivity to apomorphine and monoamine receptors following withdrawal from continuous cocaine administration in rats. Synapse 16:1-10

Neisewander JL, Lucki I, McGonigle P (1996): Changes in behavioral sensitivity to SKF-38393 and quinpirole following withdrawal from continuous cocaine administration in rats. Pharmacol Biochem Behav 53:935-942

Ohmori T, Abekawa T, Koyama T (1995): Environment modifies the expression of behavioral sensitization produced by methamphetamine: Behavioral and neurochemical studies. Behav Pharmacol 6:133-142

Parsons LH, Koob GF, Weiss F (1995): Serotonin dysfunction in the nucleus accumbens of rats during withdrawal after unlimited access to intravenous cocaine. J Pharmacol Exp Ther 374:1182-1191

Paxinos G, Watson C (1986): The Rat Brain in Stereotaxic Coordinates. New York, Academic Press

Peris J, Boyson SI, Cass WA, Curella P, Dwoskin LP, Larson G, Lin L-H, Yasuda RP, Zahniser NR (1990): Persistence of neurochemical changes in dopamine systems after repeated cocaine administration. J Pharmacol Exp Ther 253:38-44

Pettit HO, Justice JB, Jr. (1989): Dopamine in the nucleus accumbens during cocaine self-administration as studied by in vivo microdialysis. Pharmacol Biochem Behav 34:899-904

Pettit HO, Justice JB, Jr. (1991): Effect of dose on cocaine selfadministration behavior and dopamine levels in the nucleus accumbens. Brain Res 539:94-102

Pettit HO, Pan H, Parsons LH, Justice JB, Jr. (1990): Extracellular concentrations of cocaine and dopamine are enhanced during chronic cocaine administration. J Neurochem 55:798-804

Pickens R, Harris WC (1968): Self-administration of d-amphetamine by rats. Psychopharmacology 12:158-163

Robbins TW, Cador M, Taylor JR, Everitt BJ (1989): Limbicstriatal interactions in reward-related processes. Neurosci Biobehav Rev 13:155-162

Robinson TE, Camp DM (1991): The feasibility of repeated microdialysis for within-subjects design experiments: Studies on the mesostriatal dopamine system. In Robinson TE, Justice JB (eds), Microdialysis in the Neurosciences. New York, Elsevier, pp 189-234

Sorg BA, Kalivas PW (1991): Effects of cocaine and footshock stress on extracellular dopamine levels in the ventral striatum. Brain Res 559:29-36

Stewart J (1984): Reinstatement of heroin and cocaine selfadministration behavior in the rat by intracerebral application of morphine in the ventral tegmental area. Pharmacol Biochem Behav 20:917-923

Stewart J, de Wit H, Eikelboom R (1984): Role of unconditioned and conditioned drug effects in the self-administration of opiates and stimulants. Psychol Rev 91:251-268

Stewart J, Vezina P (1988): A comparison of the effects of intra-accumbens injections of amphetamine and morphine on reinstatement of heroin intravenous selfadministration behavior. Brain Res 457:287-294

Stretch R, Gerber GJ (1973): Drug-induced reinstatement of amphetamine self-administration in monkeys. Can J Psychol 27:168-177

Weiss F, Hurd YL, Ungerstedt U, Markou A, Plotsky PM, Koob GF (1992a): Neurochemical correlates of cocaine and ethanol self-administration. Annals NY Acad Sci 654:220-241

Weiss F, Markou A, Lorang MT, Koob GF (1992b): Basal extracellular dopamine levels in the nucleus accumbens are decreased during cocaine withdrawal after unlimited-access self-administration. Brain Res 593:314-318

Wise RA, Murray A, Bozarth MA (1990): Bromocriptine self-administration and bromocriptine-reinstatement of cocaine-trained and heroin-trained lever-pressing in rats. Psychopharmacology 100:355-360

Wise RA, Newton P, Leeb K, Burnette B, Pocock D, Justice JB, Jr. (1995): Fluctuations in nucleus accumbens dopamine concentration during intravenous cocaine self-administration in rats. Psychopharmacology 120: $10-20$ 